\title{
DISTÂNCIA DA ANTENA E POTÊNCIA ABSORVIDA NA CABEÇA DO USUÁRIO DE TELEFONE CELULAR PORTÁTIL
}

\author{
Álvaro. A. de Salles, Claudio Fernández e Mateus Bonadiman
}

\begin{abstract}
Resumo - Neste trabalho é apresentado o desenvolvimento de um programa para cálculo da Taxa de Absorção Específica (SAR) na cabeça e no olho de um usuário de transceptores portáteis como os telefones celulares, utilizando o método das diferenças finitas no domínio do tempo (FDTD). São mostrados os principais resultados obtidos com estas simulações e as comparações com os resultados simulados e medidos por outros autores. São também discutidas alternativas visando minimizar os riscos que a absorção do campo pode representar para a saúde dos usuários, incluindo a utilização de antenas que emitem mais no sentido oposto à cabeça.
\end{abstract}

\begin{abstract}
The development of a software to estimate the Specific Absorption Rate (SAR) in the head and in the eyes of portable transmitters (such as cellular phones) user's employing the finite difference time domain (FDTD) method is shown in this work. The relevant results obtained with this model are compared with those estimated and measured by other authors. Alternatives aiming to reduce health risks are discussed, including the use of antennas radiating energy away from the user's head.
\end{abstract}

Palavras-chave: Telefones Celulares, Efeitos Biológicos, Taxa de Absorção Específica (SAR), Diferenças Finitas no Domínio do Tempo (FDTD), Antenas em Microstrip.

\section{INTRODUÇÃO}

De alguns anos para cá tem havido uma significativa expansão dos sistemas de telefonia celular em nosso país, visando atender a uma demanda que tem crescido muito mais rapidamente que quaisquer previsões mais otimistas. Atualmente são mais que 27 milhões de usuários no Brasil, e previsões oficiais estimam que até o final do ano 2001 deverá haver cerca de 32 milhões de terminais portáteis. Juntamente com a popularização da utilização dos telefones celulares tem crescido também a preocupação da população com os possíveis riscos à saúde causados pela exposição aos campos eletromagnéticos irradiados por estes equipamentos. Estes, em sua grande maioria utilizam antenas do tipo monopolo verticais operadas via de regra muito próximas da cabeça do usuário (p.ex., $1 \mathrm{~cm}$. ou menos que isto). Estas antenas, afastadas de quaisquer obstáculos, irradiam simetricamente em um plano horizontal. Entretanto, simulações e medidas mostram que, à medida que estas antenas são aproximadas da cabeça do usuário, a potência absorvida em diferentes tecidos da cabeça cresce substancialmente, resultando no conseqüente decréscimo da

Os autores são do Departamento de Engenharia Elétrica, UFRGS. End. eletrônicos: aasalles@vortex.ufrgs.br, fdez@iee.ufrgs.br, mateus@bonadiman.com.br. potência transmitida para a Estação de Rádio Base (ERB) com a qual estão se comunicando. Nestas condições, diversos efeitos indesejáveis podem ocorrer, além dos riscos à saúde, p. ex.: (a) a ligação fica prejudicada, e o controle automático de nível de potência transmitida se ajusta para os níveis mais elevados (próximos a $250 \mathrm{~mW}$ nos aparelhos digitais, e a $600 \mathrm{~mW}$ nos modelos analógicos); (b) a carga da bateria é consumida mais rapidamente; (c) ficam também alteradas algumas características importantes como impedância de entrada da antena e seu diagrama de irradiação, entre outras.

Na segunda metade de 1999, a Anatel (Agência Nacional de Telecomunicações) divulgou a adoção provisória dos limites de exposição humana a campos eletromagnéticos não-ionizantes estabelecidos pela ICNIRP (International Comission on Non-Ionizing Radiation Protection) [1], o que posteriormente constituiu Consulta Publica visando o estabelecimento de uma recomendação oficial permanente. Estas recomendações incluem limites bastante próximos aos estabelecidos pela norma proposta pelo IEEE e adotada pela ANSI (American National Standards Institute) dos EUA [2]. Estas duas são as normas mais referenciadas internacionalmente, e ambas foram estabelecidas com base essencialmente nos "efeitos térmicos" dos campos eletromagnéticos [3,4]. Recentemente os "efeitos nãotérmicos" têm sido mais pesquisados (inclusive em experiências com cobaias), e existe a possibilidade que em um futuro próximo os limites de exposição recomendados incluam também estes efeitos [5-8]. A própria OMS (Organização Mundial da Saúde) está financiando um projeto de 5 anos orçado em US\$ 23 milhões (iniciado em 1996, e do qual fazem parte 45 países e oito organizações internacionais) em que um dos objetivos principais é o estudo destes efeitos "nào-térmicos" [9]. Entretanto, a maior parte dos resultados destes estudos deverá demorar ainda cerca de um ou dois anos mais para serem divulgados.

Para melhor caracterizar a interação da antena com a cabeça do operador, diferentes métodos numéricos para simular a absorção dos campos nos tecidos envolvidos podem ser empregados. Porque é atualmente a escolha mais apropriada e eficaz para simulação de estruturas altamente não-homogeneas, o método das Diferenças Finitas no Domínio do Tempo (FDTD) tem sido utilizado por diversos autores [10-13]. Em trabalhos anteriores, a simulação utilizando o método FDTD já havia sido mostrada com alguns detalhes [14-15].

Neste trabalho, após uma rápida discussão dos efeitos térmicos e não-térmicos, é feita uma exposição sucinta do método de simulação FDTD. Após, utilizando este método, os efeitos da variação da distância da antena à cabeça e ao olho do usuário são simulados, comparados com os resultados obtidos por outros autores e com alguns resultados medidos. Finalmente, alternativas para minimizar a absorção de energia na cabeça, incluindo resultados 
preliminares obtidos com uma antena diretiva tipo monopolo de um quarto de onda em microstrip, bem como comentários e conclusões são apresentados.

\section{EFEITOS BIOLÓGICOS}

Os principais efeitos biológicos das ondas eletromagnéticas podem genericamente ser divididos em dois tipos: (a) "Efeitos Térmicos" e (b) "Efeitos Não Térmicos", que serão considerados a seguir.

\section{1. "EFEITOS TÉRMICOS"}

Os efeitos térmicos são aqueles causados por um aquecimento direto dos tecidos biológicos como resultado da absorção da energia eletromagnética num meio dissipativo, por exemplo, nos meios dielétricos dissipativos onde a permissividade (ou constante dielétrica) apresenta uma parte imaginária maior que zero. A parte imaginária $\left(\varepsilon_{r}{ }^{\prime \prime}\right)$ da permissividade relativa de um dielétrico dissipativo pode ser relacionada a uma condutividade equivalente:

$$
\sigma=2 \pi f \varepsilon_{0} \varepsilon_{r},(S / m)
$$

onde $f$ é a freqüência e $\varepsilon_{0}$ é a permissividade do vácuo. Tanto os valores das partes real $\left(\varepsilon_{r}^{\prime}\right)$ e imaginária $\left(\varepsilon_{r}{ }^{\prime \prime}\right)$ da permissividade relativa $\left(\varepsilon_{r}=\varepsilon_{r}{ }^{\prime}+j \varepsilon_{r}{ }^{\prime \prime}\right)$, bem como da condutividade equivalente $\sigma$ variam substancialmente com a freqüência e com o tipo de tecido [16]. Ao contrário das radiações não ionizantes em comprimentos de onda menores (p.ex., no infravermelho, ou no visivel, etc.), as radiações em microondas e em rádio freqüência $(R F)$ não são somente absorvidas pela pele, mas dependendo da freqüência, em camadas mais profundas de tecidos também. Uma vez que os sensores de temperatura do corpo humano estão localizados somente na periferia do corpo, efeitos prejudiciais aos tecidos podem ocorrer devido a aquecimentos excessivos em regiões mais profundas, sem serem percebidos pelas pessoas.

Então genericamente, todos os efeitos que podem ser devidos a um aumento de temperatura nos tecidos são chamados efeitos térmicos. Estes efeitos térmicos têm sido estudados há muitas décadas [5-8], e os resultados da absorção dos eampos eletromagnéticos por diferentes tipos de tecidos são relativamente bem conhecidos, existindo mesmo normas internacionalmente aceitas que estabelecem limites de exposição em função da frequiência de operação, do tempo de exposição, do tipo de usuário, etc., [1,2]. Os limites de exposição podem ser expressos em densidade de potência incidente (p.ex., em $\mathrm{mW} / \mathrm{cm}^{2}$ ). Por outro lado, um parâmetro dosimétrico largamente utilizado é a "Taxa de Absorção Específica" (ou SAR - "Specific Absorption Rate"), que é definida como "a derivada no tempo do aumento de energia " $\partial W$ " absorvida ou dissipada num elemento de massa " $\partial m$ " contida num elemento de volume " $\partial V "$ cuja massa específica é " $\rho "$ " [4,17], e que analiticamente pode ser expressa por:

$$
S A R=\frac{\partial}{\partial t} \frac{\partial W}{\partial m}=\frac{\partial}{\partial t} \frac{\partial W}{\partial(\partial V)}(m W / g)
$$

Daí é possivel, em outras palavras, dizer-se que a SAR quantifica a potência absorvida por unidade de massa.
Utilizando o teorema do Vetor de Poynting para campos eletromagnéticos com excitação senoidal no domínio da freqüência, a SAR pode ser também expressa por:

$$
S A R=\frac{\sigma}{2 \rho}|E i|^{2}=\frac{\sigma \varepsilon_{0} \varepsilon_{r}{ }^{\prime \prime}}{2 \rho}|E i|^{2}=\frac{\left|J_{1}\right|^{2}}{2 \rho \sigma}(m W / g)
$$

onde $E_{i}$ e $J_{i}$ são os valores de pico do campo elétrico e da densidade de corrente no local considerado. Observa-se que a SAR é diretamente proporcional ao aumento local de temperatura, responsável pelos efeitos térmicos:

$$
\frac{\partial T}{\partial t}=\frac{S A R}{C_{P}}\left({ }^{\circ} \mathrm{C} / s\right)
$$

onde $T$ é a temperatura, e $C_{p}$ é o calor específico do tecido $\left(\mathrm{J} / \mathrm{kg}{ }^{\circ} \mathrm{C}\right)$. Para exposição do corpo inteiro, por exemplo, pode-se considerar a SAR média, que será então a relação entre a potência total absorvida pelo corpo e sua massa. Entretanto, para aquecimentos localizados, como os produzidos pelos telefones celulares emitindo muito próximos (p.ex., a $2 \mathrm{~cm}$. $1 \mathrm{~cm}$ ou menos) da cabeça do usuário, deve ser usada a SAR local, que é definida como a potência absorvida (em $\mathrm{mW}$, p. ex.) por um grama de tecido. Pela norma IEEE/ANSI, para as frequências do celular no Brasil, a SAR de $1,6 \mathrm{~mW} / \mathrm{g}$ não deve ser ultrapassada.

\section{2. "EFEITOS NÃO-TÉRMICOS"}

Os efeitos "não-térmicos" são, por exemplo, efeitos bioquímicos ou eletrofísicos causados diretamente pelos campos eletromagnéticos induzidos, e não indiretamente por um aumento localizado ou distribuído de temperatura. Alguns efeitos "não-térmicos" reportados na literatura incluem efeitos nos sistemas nervoso, cardiovascular e imunológico, bem como no metabolismo e em fatores hereditários [5-7]. Entretanto, nestas áreas os resultados ainda são polêmicos, não existindo via de regra conclusões definitivas, o que poderá ainda demorar muitos anos. Alguns resultados são mesmo conflitantes, especialmente devido a técnicas experimentais não muito confiáveis. Por exemplo, (a) os métodos utilizados para caracterizar os sintomas em estudos epidemiológicos: (b) dosimetria em RF e microondas, especialmente em campo próximo; e (c) a presença de influências estranhas não consideradas na interpretação dos resultados.

Efeitos que foram claramente demonstrados incluem a alteração no fluxo de íons através das membranas das células (afetando particularmente as propriedades eletrofisiológicas das células nervosas), alteração na mobilidade dos íons de cálcio (particularmente nos tecidos do cérebro), alterações na síntese de DNA e na transcrição de RNA e efeitos na resposta de células normais a moléculas sinalizantes (incluindo hormônios, neurotransmissores e fatores de crescimento) [6]. Alterações no fluxo de cálcio em células, na barreira hemato-encefálica ("blood-brain barrier", que protege o cérebro de certas toxinas) e no desenvolvimento de tumores cerebrais foram também reportados [16].

Entre outras, uma incerteza importante que está para ser confirmada é se estes efeitos não térmicos podem ou não ocorrer em taxas de absorção específicas bem abaixo daquelas observadas para os efeitos térmicos. Efeitos no 
sistema imunológico foram constatados em cobaias quando a SAR era maior que $0,4 \mathrm{~mW} / \mathrm{g}$, as células nervosas eram influenciadas quando os valores de $\mathrm{SAR}$ eram superiores a $2 \mathrm{~mW} / \mathrm{g}$ e exposição a SAR entre 2 e $3 \mathrm{~mW} / \mathrm{g}$ promoveu a ocorrência de câncer ou carcinomas em ratos [6]. Além disto, alterações no sistema endócrino e na quimica sangüínea foram relatados quando a $\mathrm{SAR}$ é maior que $1 \mathrm{~mW} / \mathrm{g}$ e alterações nos sistemas hematológicos e imunológicos ocorrem quando a SAR é igual ou maior que $0,5 \mathrm{~mW} / \mathrm{g}$ para exposições prolongadas [17]. Alguns autores resumem os dados experimentais em cobaias sugerindo que os efeitos aparecem em SAR médias entre 1 a $4 \mathrm{~mW} / \mathrm{g}$, e isto tem sido um critério adotado nas normas mais recentes [1.7].

Recentemente, foi reportada a indução de proteinas de choque térmico (HSP- "Heat-Shock Proteins") em vermes do tipo nematóides ("Caenorhabditis Elegans") com exposição prolongada a campos eletromagnéticos de baixa intensidade (SAR de $0,001 \mathrm{~W} / \mathrm{Kg}$, em $750 \mathrm{MHz}$ ), o que foi atribuído a mecanismos não térmicos que podem também ocorrer em tecidos humanos [18,19]. Isto sugere então que os limites atuais de exposição devem ser reconsiderados.

Revendo a literatura, observa-se que, à medida que as pesquisas avançam e novos resultados aparecem, as normas são atualizadas e, novos limites mais restringentes, são sugeridos [1-2]. Entre as muitas dúvidas que ainda estão por ser esclarecidas é possível ressaltar-se, por exemplo, como o campo eletromagnético atua em determinadas estruturas, como: (a) nos cromossomos ou nas moléculas de DNA que constituem os genes [16], e (b) na alteração da mobilidade dos íons (p.ex., de cálcio), particularmente em tecidos do cérebro e nas propriedades eletro-fisiológicas das células nervosas [6]. Por outro lado, é sabido que um estágio inicial do desenvolvimento do câncer é caracterizado por uma alteração no código genético de células do corpo. isto é, a molécula de DNA.

\section{ALGORITMO FDTD}

Para prever o atendimento aos limites recomendados em [1.2] para o caso dos transmissores portáteis é necessário encontrar soluções de campo próximo e em meios altamente heterogêneos. Estas soluções requerem métodos de cálculo numéricos, como o das diferenças finitas no domínio do tempo FDTD. que foi usado nestas simulações.

\subsection{CÁLCULO DOS CAMPOS ELÉTRICOS E MAGNÉTICOS}

O método FDTD resolve as equações diferenciais de Maxwell, em forma de diferenças finitas, num dominio de cálculo previamente discretizado [20]. O algoritmo implementa as equações (5) a (10), que diferem das equaçōes originalmente propostas, pelo fato de avaliar os rotacionais no intervalo de discretização inteiro e não em intervalos de $1 / 2$, evitando a duplicação da malha. As equações originais são baseadas na célula de Yee, como mostra a Figura 1.
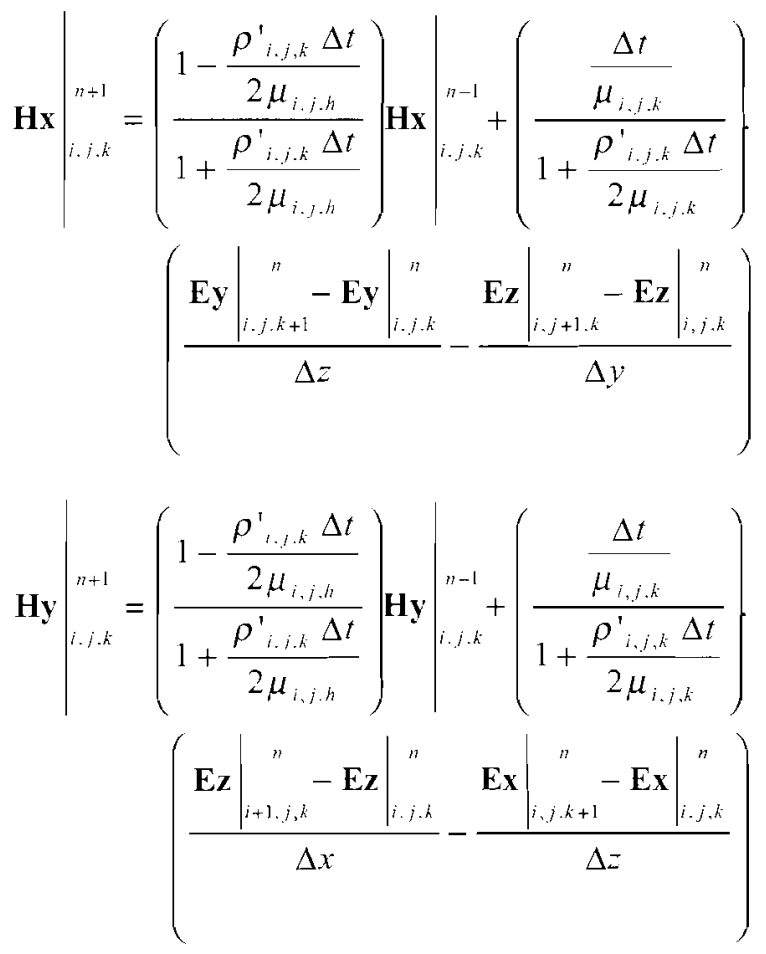

$$
\begin{aligned}
\left.\mathbf{H z}\right|_{i, j, k}= & \left.\left(\frac{1-\frac{\rho_{i, j, k}^{\prime} \Delta t}{2 \mu_{i, j . h}}}{1+\frac{\rho_{i, j, k}^{\prime} \Delta t}{2 \mu_{i, i, h}}}\right)^{\prime}\right|_{i, j, k}+\left(\frac{\frac{\Delta t}{\mu_{i, j, k}}}{1+\frac{\rho_{i, j, k}^{\prime} \Delta t}{2 \mu_{i, j, k}}}\right) \\
& \left(\frac{\left.\mathbf{E x}\right|_{i, i+1 . k} ^{n}-\left.\mathbf{E x}\right|_{i, j . k} ^{n}}{\Delta x}-\frac{\left.\mathbf{E y}\right|_{i+1, j, k} ^{n}-\left.\mathbf{E y}\right|_{i, j, k} ^{n}}{\Delta z}\right)
\end{aligned}
$$

$$
\begin{aligned}
\left.\mathbf{E x}\right|_{i, j, k} ^{n+1} & =\left.\left(\frac{1-\frac{\sigma_{i, j, k} \Delta t}{2 \varepsilon_{i, j, h}}}{1+\frac{\sigma_{i, j, k} \Delta t}{2 \varepsilon_{i, j, h}}}\right) \mathbf{E x}\right|_{i, j, k}+\left(\frac{\frac{\Delta t}{\varepsilon_{i, j, k}}}{1+\frac{\sigma_{i, j, k} \Delta t}{2 \varepsilon_{i, j, k}}}\right) \\
& \left(\frac{\left.\mathbf{H z}\right|_{i, j, k} ^{n+1}-\left.\mathbf{H z}\right|_{i, 1-1, k} ^{n+1}}{\Delta y}-\frac{\left.\mathbf{H y}\right|_{i, j, k} ^{n+1}-\left.\mathbf{H y}\right|_{i, j, k-1} ^{n+1}}{\Delta z}\right)
\end{aligned}
$$

$$
\begin{aligned}
\left.\mathbf{E y}\right|_{i, j . k} ^{n+1} & =\left.\left(\frac{1-\frac{\sigma_{i, j, k} \Delta t}{2 \varepsilon_{i, j, h}}}{1+\frac{\sigma_{i, j, k} \Delta t}{2 \varepsilon_{i, j, h}}}\right) \mathbf{E y}\right|_{i, j, k} ^{n}+\left(\frac{\frac{\Delta t}{\varepsilon_{i, j, k}}}{1+\frac{\sigma_{i, j, k} \Delta t}{2 \varepsilon_{i, j, k}}}\right) \\
& \left(\frac{\left.\mathbf{H} \mathbf{x}\right|_{i, j, k} ^{n+1}-\left.\mathbf{H} \mathbf{x}\right|_{i, j, k-1} ^{n+1}}{\Delta z}-\frac{\left.\mathbf{H z}\right|_{i, j, k} ^{n+1}-\left.\mathbf{H z}\right|_{i-1, j, k} ^{n+1}}{\Delta x}\right)
\end{aligned}
$$


$\begin{aligned}\left.\mathbf{E z}\right|_{i, y, k} & =\left.\left(\frac{1-\frac{\sigma_{i, j, k} \Delta t}{2 \varepsilon_{i, j, h}}}{1+\frac{\sigma_{i, j, k} \Delta t}{2 \varepsilon_{i, j, h}}}\right) \mathbf{E z}\right|_{i, j, k} ^{n}+\left(\frac{\frac{\Delta t}{\varepsilon_{i, 1, k}}}{1+\frac{\sigma_{i, j, k} \Delta t}{2 \varepsilon_{i, j, k}}}\right) \\ & \left(\frac{\left.\mathbf{H y}\right|_{i, j, k} ^{n+1}-\left.\mathbf{H y}\right|_{i-1, j, k} ^{n+1}}{\Delta x}-\frac{\left.\mathbf{H x}\right|_{i, 1, k} ^{n+1}-\left.\mathbf{H x}\right|_{,, j-1, k} ^{n+1}}{\Delta y}\right)\end{aligned}$

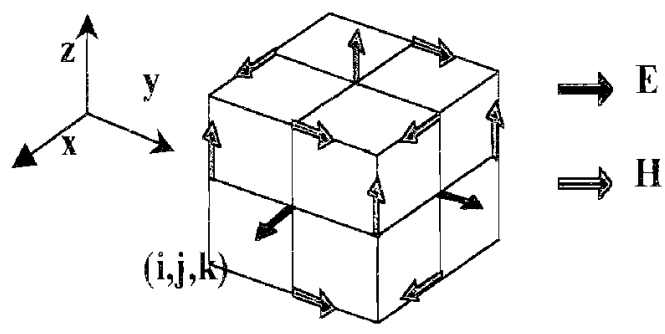

Figura 1. Célula de Yee.

\subsection{CONVERGÊNCIA}

Os critérios de convergência do algoritmo desenvolvido são os mesmos de um algoritmo FDTD genérico. Por exemplo, para o caso de uma malha de discretização homogênea com $\Delta x=\Delta y=\Delta z=0,9 \mathrm{~mm}$ e para uma onda propagante de freqüência igual a $850 \mathrm{MHz}$, o intervalo de tempo entre iterações deve ser menor ou igual que $\Delta \mathrm{t}=3,4665 \times 10^{-12}$ segundos. Para estes valores de $\Delta x=\Delta y=\Delta z$, e do tempo $\Delta t$ entre iterações, se demonstra que o resultado da solução numérica (nos pontos onde é calculada) é exato, idêntico ao da solução algébrica, se esta existir, sendo cancelados os erros de quantização, tendo apenas o erro derivado do truncamento computacional. Por estas propriedades, este intervalo de tempo é chamado de "Magic Step" [20].

\subsection{SIMULAÇÃO DO ESPAÇO LIVRE E ESTABILIDADE}

Um problema que os algoritmos FDTD devem considerar é a simulação do espaço livre. O domínio computacional é İecessariamente finito, então o domínio de simulação deve ser truncado. A primeira aproximação para uma condição de contorno na borda do domínio seria a de supor os campos suficientemente atenuados para considerarmos o seu valor nulo. Porém, imediatamente podem ser observadas as semelhanças entre esta solução e a modelagem de uma superfície metálica, perfeitamente condutora e, portanto, refletora. Este tipo de truncamento provoca então, reflexões da onda propagante nas bordas do domínio [20]

Entre as diferentes soluções propostas (como p.ex., cálculo do valor da condição de contorno usando equações de campo distante, uso de equações e algoritmos específicos para as regiões limites do domínio, etc) foi escolhido, após alguns ensaios com outros métodos, utilizar um material de borda com características absorvedoras ("ABC"), como a Perfect Matching Layer ("PML") [21-23]
Foi implementada, então, uma camada absorvedora de uma profundidade de 30 células do domínio com diferentes materiais com características anisotrópicas de condutividade. Com esta solução são obtidas atenuações superiores a $30 \mathrm{~dB}$ na reflexão, e já foram relatadas atenuações de mais de $70 \mathrm{~dB}$ por outros autores $[21,23]$.

\subsection{VALIDAÇÃO}

Parte fundamental das simulações numéricas consta na confiabilidade dos resultados obtidos. Mesmo observadas as condições matemáticas de estabilidade e convergência e avaliados os erros de truncamento, são necessários o teste do algoritmo com problemas dos quais se conhece a solução. No caso presente, embora não se tenha testado o programa com uma bateria completa de problemas "benchmarks", foi comprovada a resposta do mesmo para a propagação de pulsos e ondas senoidais em meios homogêneos, observando os fenômenos mais conhecidos de mudança de comprimento de onda na interface entre dois meios, reflexões e difração em fendas. Para a simulação da propagação de uma onda no ar foi medida uma velocidade de propagação Je $303.000 .000 \mathrm{~m} / \mathrm{s}, 1 \%$ acima da velocidade da luz, erro este inferior ao que pode ser justificado pela discretização do domínio.

\section{SIMULAÇÃO DO TRANSMISSOR}

Algoritmos FDTD foram utilizados em cálculos precisos de propagação da onda eletromagnética do telefone celular portátil na cabeça do usuário, visando estimar seus possíveis efeitos quanto à absorção de energia pela cabeça [10-15].

Embora os efeitos térmicos estejam na origem das limitações recomendadas, estas aparecem em valores de campo. Para comparação com as limitações basta então calcular os campos. Nas simulações apresentadas se calculam apenas os campos eletromagnéticos sem levar em conta a troca de calor do corpo ou a variação dos parâmetros dos tecidos em função da variação da temperatura.

O aigoritmo para o cálcuio da SAR, parte do reconhecimento de 1 magens médicas [24], que determinam o domínio numérico onde o campo é calculado utilizando o método FDTD. Após a determinação do espaço físico do problema, através de um conjunto de imagens bidimensionais, o programa cria uma matriz para cada imagem capturada. Cada célula desta matriz estará relacionada a uma localização no espaço e, portanto a um tecido específico, referente a sua posição. É simulado então um dipolo magnético, que será a condição de contorno do método numérico ou a fonte do campo eletromagnético e se faz com que este assuma as características semelhantes à antena de um aparelho celular, onde se tem freqüência e potência pré-estabelecidas. Estas ondas se propagam a partir da fonte, desde uma condição inicial de campos nulos em todo o domínio, e através de um número elevado de iterações, penetram na cabeça do usuário. Após a convergência numérica, o valor de campo calculado em todas as iterações é utilizado para o cálculo da SAR em cada célula do domínio. Estes dados calculados são armazenados novamente em matrizes e transformados posteriormente em novas imagens, através das quais, 
é possível visualizar as distribuições de intensidade de campo e da SAR. Nestas simulações, por simplificação, não foram incluídos no modelo os seguintes elementos: aparelho, mão e tronco do usuário.

Neste trabalho são apresentados resultados de simulações para duas configurações: (a) quando o transmissor está localizado ao lado da cabeça, caso do usuário de telefone celular, e (b) quando o transmissor é colocado frontalmente ao usuário, caso de muitos serviços de radiocomunicações. $\mathrm{Na}$ Figura 2, têm-se esquemas dos dois tipos de configurações simuladas.

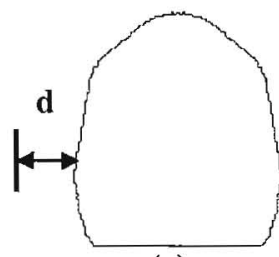

(a)

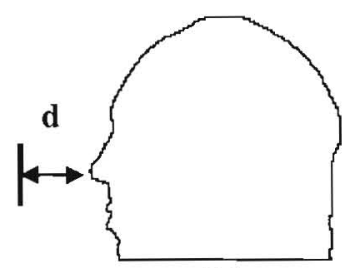

(b)
Figura 2. Modelos de estudo: (a) caso do telefone celular e (b) caso visando o efeito no olho.

\subsection{MODELAMENTO DO DOMINIO}

O modelo da cabeça do usuário desenvolvido para este trabalho, foi obtido a partir de imagens médicas disponíveis. No total foram usadas 208 imagens de cortes sagitais, com espaçamento de $0,9 \mathrm{~mm}$ entre imagens sucessivas, o que possibilitou um modelamento preciso e detalhado dos tecidos internos à cabeça. Para cada corte são disponíveis imagens de cortes reais, de Raios-X e de Ressonância Magnética, sendo que estes três tipos de imagens foram utilizados para a definição do modelo (Figura 3).

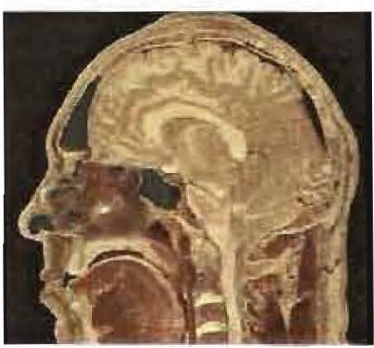

(a)

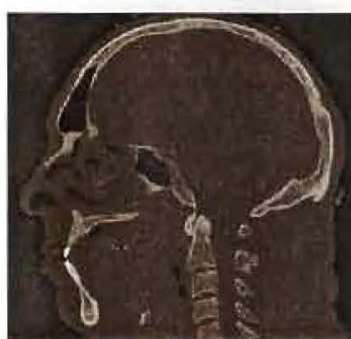

(b)
Figura 3. Imagens médicas obtidas. (a) Corte Sagital da Cabeça, e (b) Raio-X do mesmo corte.

Cada imagem é composta de $225 \times 256$ pontos ou pixels, compondo uma malha de 57.600 células por corte, totalizando aproximadamente 12 milhões de pontos. As dimensões do modelo utilizado (mostradas na Figura 4) são compatíveis com as dos modelos recomendados [25] e com as apresentadas em trabalhos de outros autores [10].
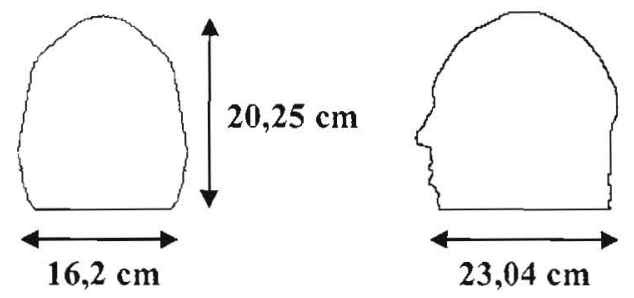

Figura 4. Dimensões do modelo de cabeça utilizado.
Utilizando ferramentas gráficas, foram separados, de forma simplificada, em cada imagem, os diferentes tecidos que a compõe e que serão considerados homogêneos e invariantes nos cálculos: pele/gordura, músculos, ossos, cérebro, olhos e o próprio ar, usando para isto cores primárias para maior facilidade em posterior reconhecimento destas pelo algoritmo (Figura 5).
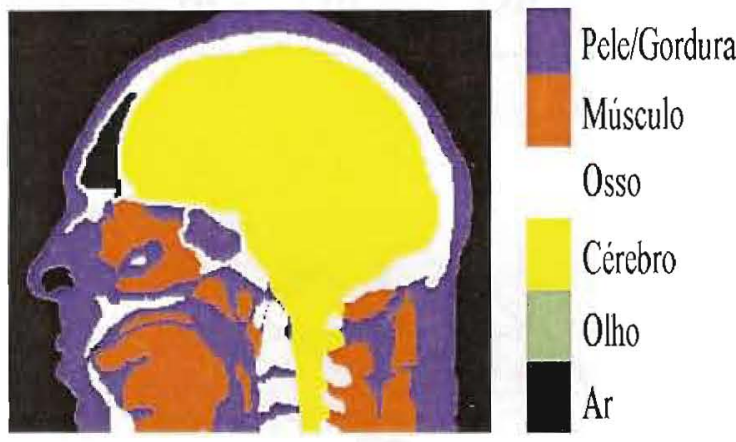

Figura 5. Imagem simplificada de um corte sagital da cabeça com seus tecidos identificados por cores. Esta imagem representa um plano da matriz domínio.

A partir deste conjunto de imagens simplificadas, convertidas em arquivo "bitmap", é fácil identificar em cada ponto o tecido correspondente ao mesmo (reconhecimento do padrão RGB). Indexando um valor a cada tecido, podese extrair uma matriz numérica bidimensional (Figura 6) de modo que durante o processamento da simulação, obtém-se através da soma das 208 matrizes correspondentes aos 208 cortes sagitais, uma matriz tridimensional (3D), representando o domínio do problema com a composição de 11.980 .800 células.

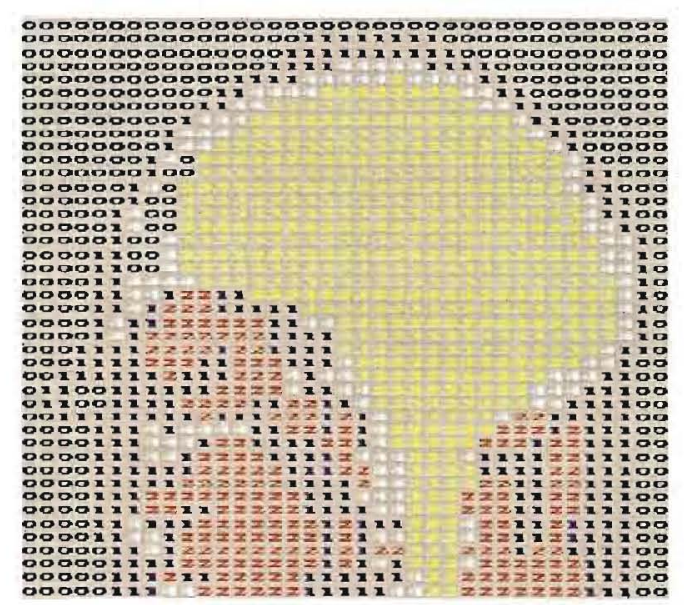

Figura 6. Ilustração de uma matriz, onde cada índice, aqui representado por cores diferentes, corresponde a um tecido.

Os diferentes meios que constituem o modelo da cabeça foram definidos de acordo com os parâmetros eletromagnéticos médios dos diferentes tecidos presentes [10,26, 27]. Assim tecidos que apresentam valores semelhantes foram considerados, por simplicidade, como um único meio. Desde que essas características são dependentes da freqüência da radiação à qual são submetidos, os parâmetros correspondem à freqüência simulada $(850 \mathrm{MHz})$. A Tabela 1 expressa os parâmetros utilizados em nossas simulações. 


\begin{tabular}{llll}
\hline \multicolumn{1}{c}{ Tecido } & $\varepsilon_{\mathrm{r}}$ & $\boldsymbol{\sigma}[\mathrm{S} / \mathrm{m}]$ & $\rho[\mathrm{Kg} / \mathbf{}]$ \\
\hline Pele/Gordura & 34.5 & 0.600 & 1.10 \\
Músculo & 58.5 & 1.210 & 1.04 \\
Osso & 8.0 & 1.105 & 1.85 \\
Cérebro & 55.0 & 1.230 & 1.03 \\
Olho & 67.9 & 1.680 & 1.02 \\
\hline
\end{tabular}

Tabela 1, Parâmetros dos tecidos usados na simulação.

Analisando os valores da tabela acima, juntamente com a equação (3), podemos observar que os valores elevados para a constante dielétrica relativa provocam uma concentração de densidade de fluxo elétrico em alguns tecidos, o que associado aos altos valores de condutividade, irá resultar em SAR elevada.

\subsection{MODELAMENTO DO MONOPOLO}

Muitos aparelhos celulares utilizados atualmente são dotados de antenas tipo monopolo, dipolo ou helicoidal, que apresentam diagramas de irradiação simétricos no plano horizontal, quando afastados de qualquer obstáculo. A Figura 7 mostra o diagrama de irradiação de um monopolo vertical, comparado com uma fonte isotrópica (bi e tridimensional). Quando da presença de um corpo no campo próximo da antena, estes diagramas ficam substancialmente alterados.

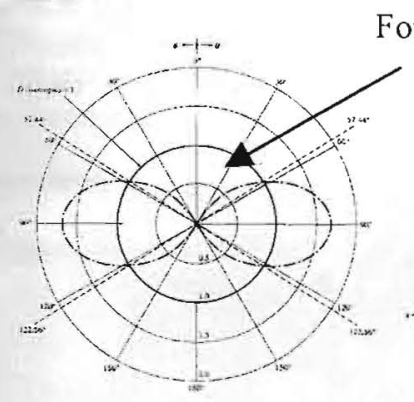

(a)
Fonte isotrópica

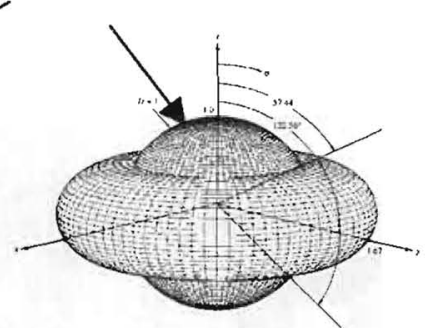

(b)

Figura 7. Diagrama de irradiação de um monopolo vertical comparado com uma fonte isotrópica: (a) bidimensional e (b) tridimensional.

Existem diferentes maneiras de modelar a fonte irradiadora. Como primeira aproximação, uma vez definidos os pontos do espaço onde estará localizada a antena, é possível forçar nestes o valor do campo elétrico tangencial (paralelo à direção principal da mesma), ou o campo magnético nas células da vizinhança de um plano normal à direção da antena, ajustado aos valores de corrente na antena, ou ainda ambos campos $\mathrm{E}$ e $\mathrm{H}$ simultaneamente. Neste caso, os pontos do domínio que representam a antena formam parte de uma coluna da matriz, e aparecerão no algoritmo como uma fonte de sinal ou "porta de entrada" eletromagnética.

Uma aproximação mais precisa consiste em descrever o material da antena (metal) como condutor ideal (sem perdas) assumindo a condutividade do metal tendendo ao infinito $(\sigma \rightarrow \infty)$. Com essa aproximação, as equações de cálculo de campo elétrico, (8) a (10), vão sofrer simplificações. Uma possível alternativa é manter as equações gerais, utilizando um valor de condutividade

apropriado. A antena utilizada nas simulações é um modelo de monopolo como apresentado na Figura 8 . O número de células destas figuras não guarda proporção com as utilizadas neste trabalho.

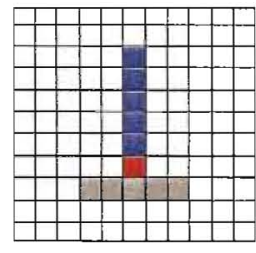

(a)

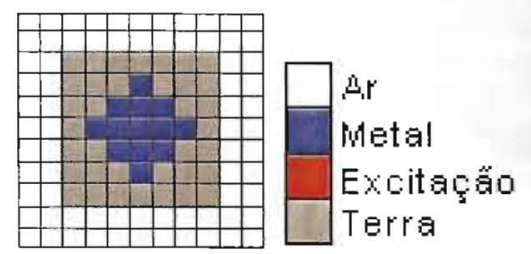

(b)
Figura 8. Representação do modelo da antena simulada: (a) vista frontal. (b) vista superior

Para a validação do modelamento, foram realizadas diversas simulações sem o obstáculo representado pela cabeça (i.é. com a antena num domínio contendo somente ar). Após um número de iterações suficiente para a convergência dos valores de campo, observa-se, a partir dos valores na matriz de $|E|$, a isotropia na propagação, o comprimento de onda, a velocidade de propagação, etc, como ilustrado na Figura 9.

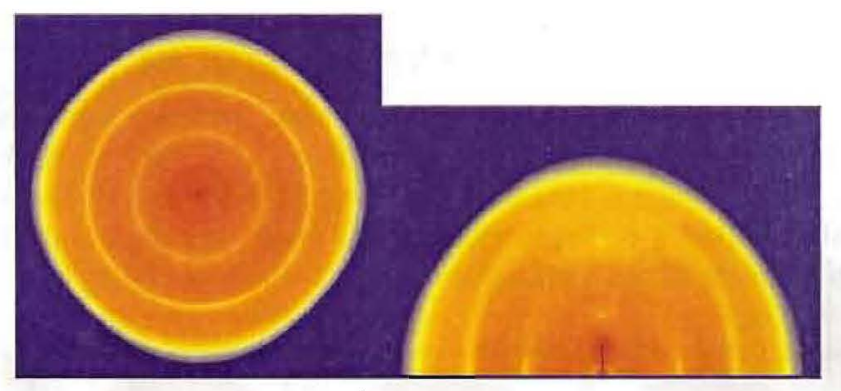

Figura 9. Imagens da simulação do monopolo no ar: vista superior (esquerda) e vista frontal (direita).

Em seqüência serão apresentados os resultados obtidos para a simulação da taxa de absorção na cabeça.

\subsection{RESULTADOS OBTIDOS}

Para comparação com as recomendações $[1,2]$, os resultados podem ser expressos em densidade de potência (p.ex., em $\mathrm{mW} / \mathrm{cm}^{2}$ ), ou na forma de SAR. Na Figura 10 , está representada a SAR ( $\mathrm{em} \mathrm{mW} / \mathrm{g})$ simulada na cabeça do usuário, normalizada para um campo elétrico de $1 \mathrm{~V} / \mathrm{m}$ RMS na antena, onde o plano horizontal representa um corte sagital da cabeça e no eixo vertical estão os valores da SAR.

Os valores obtidos nas simulações dependem de muitas variáveis do modelo, mas principalmente do posicionamento da antena em relação ao usuário, e ultrapassam em muitos casos os valores sugeridos nas normas (p.ex., SAR $=1,6 \mathrm{~mW} / \mathrm{g}$ na norma ANSI [2] ou $\mathrm{SAR}=2,0 \mathrm{~mW} / \mathrm{g}$ na norma ICNIRP [1]). A definição da posição relativa da antena à cabeça do usuário para efeitos de comprovação do atendimento à norma ICNIRP tanto em simulações como em medidas tem sido discutida recentemente [25]. 


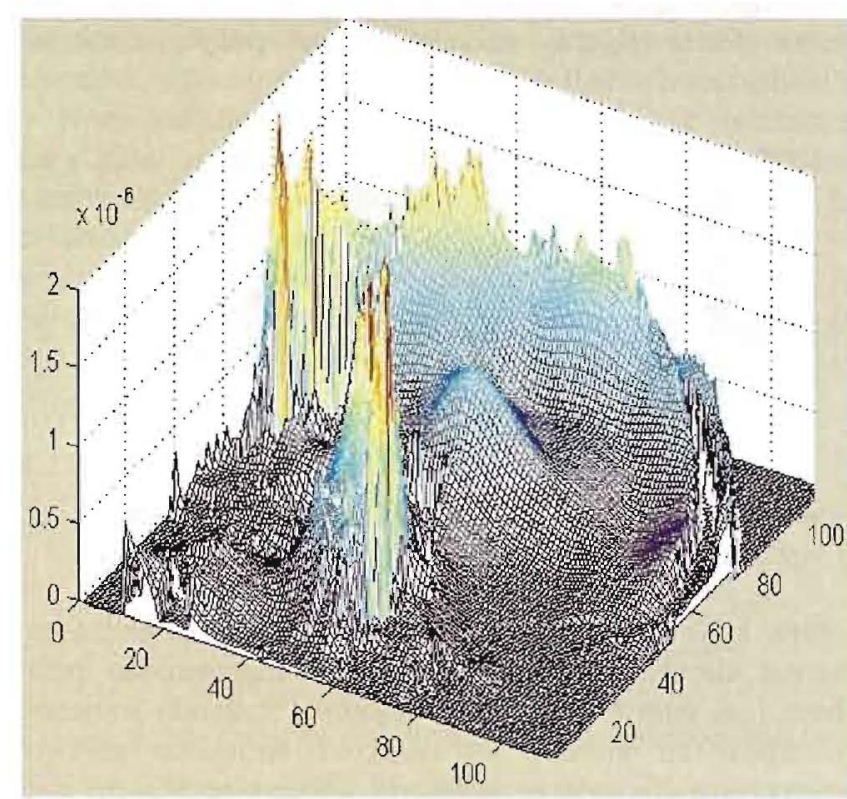

Figura 10. SAR na cabeça do usuário $\mathrm{em} \mathrm{mW} / \mathrm{g}$ por $\mathrm{V} / \mathrm{m}$ RMS. Corte Sagital.

\subsubsection{ESTUDO DO EFEITO DO CELULAR}

O algoritmo FDTD fornece em cada iteração, soluções aproximadas do valor de campo e SAR, no instante correspondente a essa iteração. Assim é possível visualizar através dele a evolução espacial das ondas se propagando e o aumento da SAR até a convergência como na Figura 11.

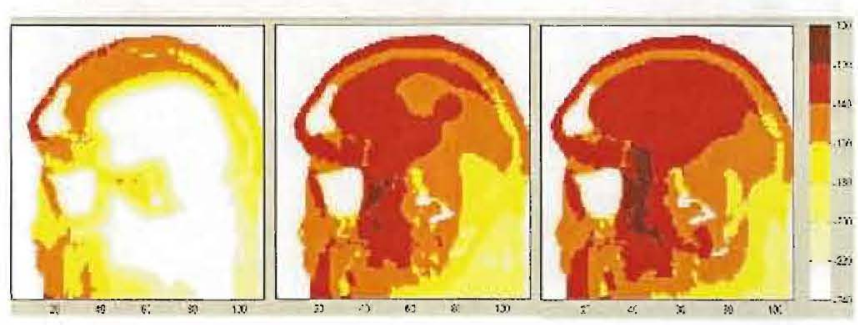

Figura 11. Imagem obtida da SAR da cabeça do usuário para um corte sagital, depois de $1 \mathrm{~ns}$, 2ns e 3 ns de exposição.

A escala de cor das figuras acima representa $\mathrm{mW} / \mathrm{g}$ de SAR por $\mathrm{V} / \mathrm{m}$ RMS de campo da fonte (i.é., num ensaio onde a fonte foi modelada como de $1 \mathrm{~V} / \mathrm{m}$ RMS) em escala logarítmica $(10 * \log (\mathrm{SAR}))$. As três figuras correspondem a 300,600 e 900 iterações ou aproximadamente tempos de $1 \mathrm{~ns}, 2$ ns e 3 ns.

Os valores obtidos na convergência numérica do método podem ser comparados dependendo da distância e posição onde a antena é colocada, e observados para diferentes cortes (Figura 12), comprovando a profundidade de penetração dos valores mais elevados da SAR (Figura 13).

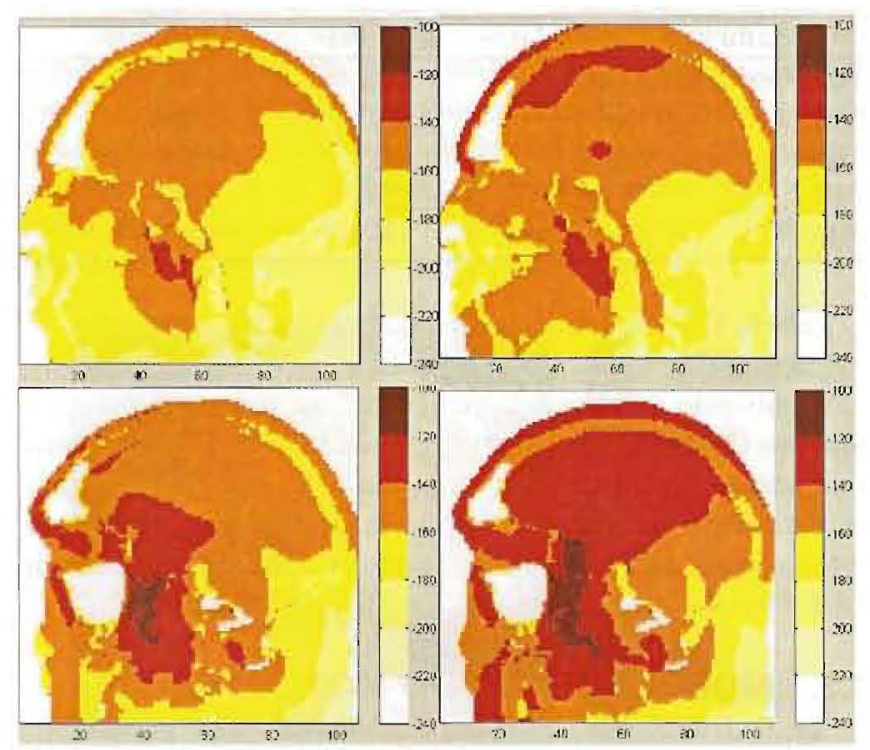

Figura 12. Imagens obtidas da SAR da cabeça do usuário para dois cortes, mais distante à antena (acima) e mais próximo (abaixo). Quando a antena é colocada a $2 \mathrm{~cm}$ (esquerda) e $1 \mathrm{~cm}$ (direita).

Em todas as Figuras 11 a 13, obtidas após 900 iterações, correspondendo a um tempo de exposição de 3,12 ns, salvo as especificadas das Figuras 11 pode-se observar que a SAR é muito intensa nas áreas do cérebro próximas ao plano da antena, e pode-se notar máximos locais em tecidos sensiveis, p.ex. nos olhos (Figura 13).

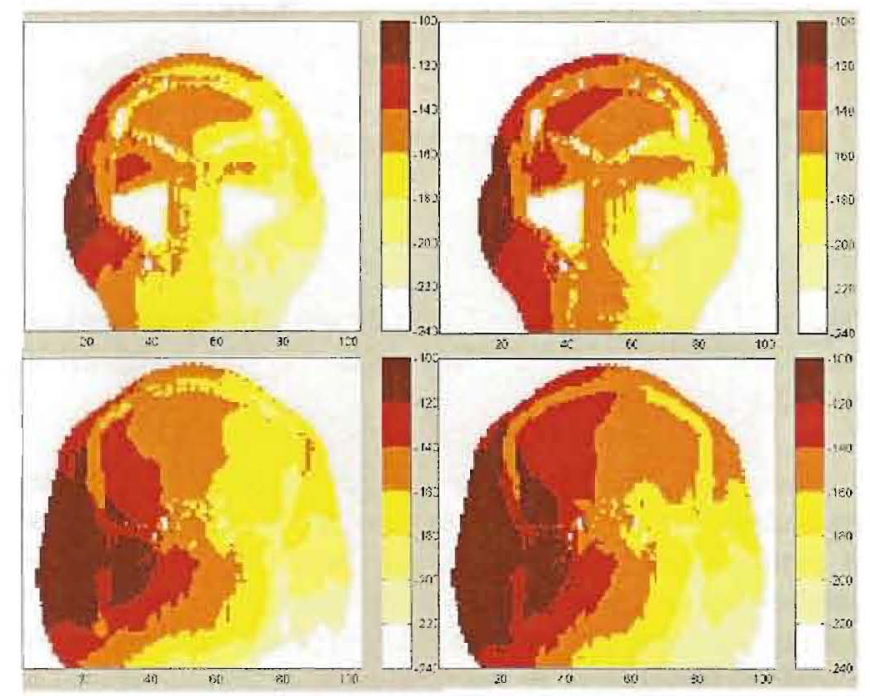

Figura 13. Os cortes transversais, neste caso na altura dos olhos (acima) e no plano da antena (abaixo) permitem observar elevados valores no interior da cabeça, para a antena a $2 \mathrm{~cm}$ e $1 \mathrm{~cm}$, (esquerda e direita respectivamente).

$\mathrm{Na}$ Figura 14 a potência entregue à antena é $P_{\text {del }}=600 \mathrm{~mW}$, para reproduzir o caso de um telefone celular operando no modo analógico. A escala de cor corresponde à SAR normalizada $[10 \log (\mathrm{SAR})]$ onde $0 \mathrm{~dB}$ corresponde a uma $\mathrm{SAR}=1 \mathrm{~mW} / \mathrm{g}$, então, o valor superior da cor mais escura (10 dB acima) corresponde a $10 \mathrm{~mW} / \mathrm{g}$. 


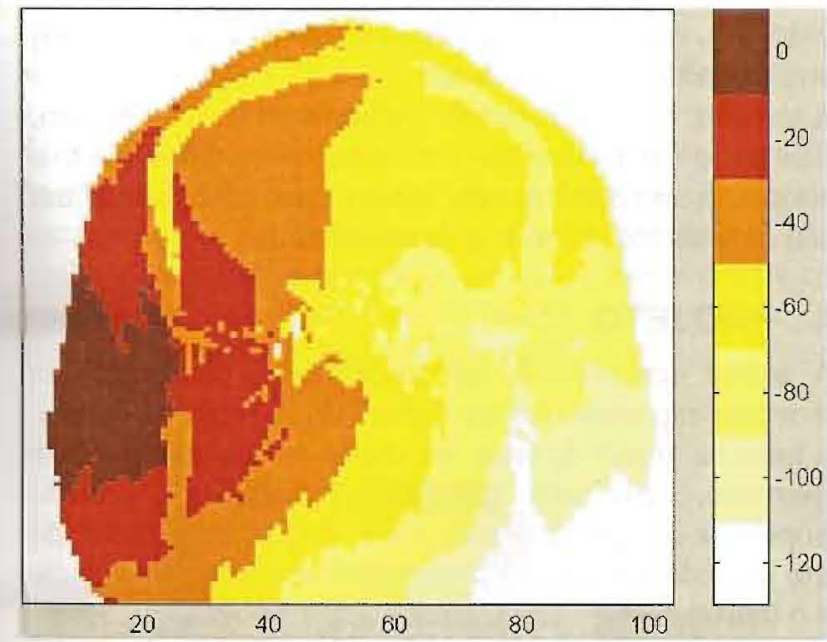

Figura 14. Imagem transversal que apresenta os resultados normalizados $[10 \log (\mathrm{SAR})]$, para uma potência entregue à antena $\mathrm{P}_{\mathrm{del}}=600 \mathrm{~mW}$.

\subsubsection{ESTUDO DO EFEITO NO OLHO}

Os resultados da SAR obtidos nestas simulações, para diferentes posições e distâncias da antena, assim como os relatados em [10-13, 26, 27], mostram que, em algumas dessas situações, os limites das normas $[1,2]$ são superados. Para uma simulação com a antena posicionada frente ao olho, como é comum no uso de alguns transmissores portáteis, mostra resultados que superam amplamente as recomendações, Figuras 15 e 18.

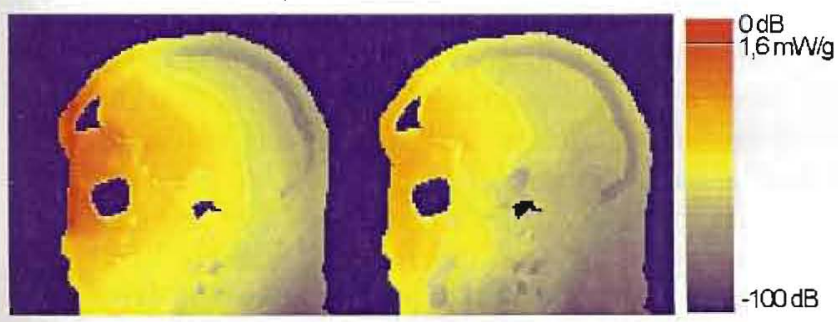

Figura 15. Imagens obtidas da $\mathrm{SAR}$. Na imagem à esquerda a antena está localizada a $0,54 \mathrm{~cm}$ do olho, e, à direita, a $3,78 \mathrm{~cm}$. [0 dB $=2,5 \mathrm{~mW} / \mathrm{g}]$.

\subsection{COMPARAÇÃO COM OUTROS AUTORES}

Considerando os estudos realizados por outros autores que utilizam diferentes métodos numéricos computacionais ou até mesmo medidas em Phantoms, é possível verificar uma similaridade muito grande nas conclusões dos diferentes estudos [10-13, 26, 27]. A presença de áreas de concentração de campo e o cálculo de valores elevados acima das recomendações são referidos na maioria dos trabalhos que abordam estas simulações. Uma comparação mais direta com os resultados dos diferentes trabalhos requer, porém reproduzir exatamente os diferentes parâmetros da simulação, como a distância, posição, características da antena entre outros. Dadas as variadas possibilidades de modelagem, e de apresentação dos resultados os diversos autores encontram pequenas diferenças nos seus resultados, mas numa análise geral, pode-se concluir que as áreas mais afetadas pelo efeito do campo eletromagnético, obtidas neste trabalho, são equivalentes e com valores muito aproximados aos obtidos por outros autores (Figuras 16 a 18).

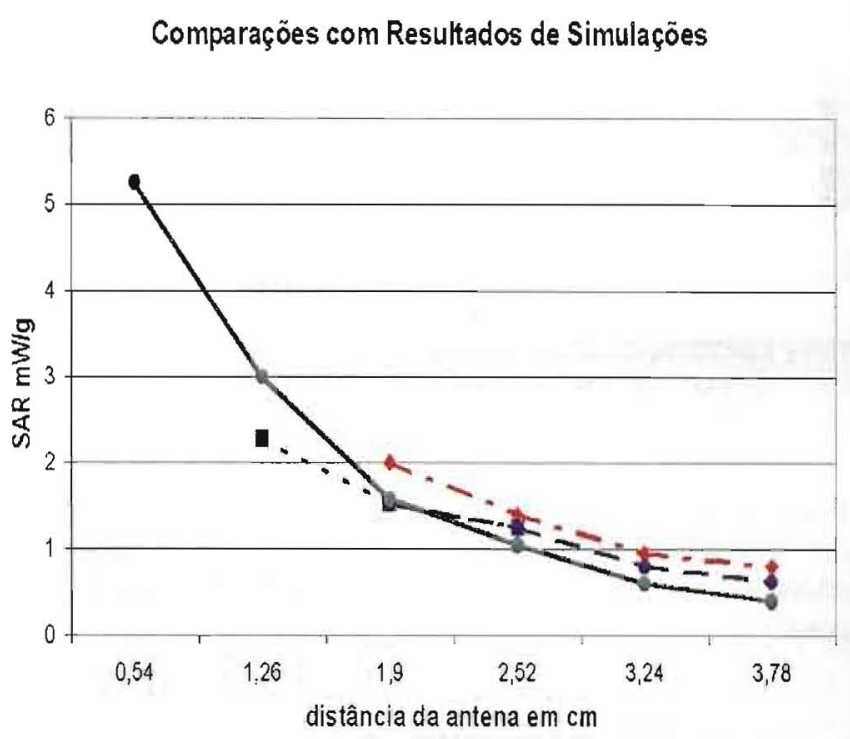

Figura 16. Gráfico da SAR simulada na cabeça do usuário. A curva verde obtida neste trabalho (para $31.6 \mathrm{Vpp} / \mathrm{m}$ ) é comparada com as curvas de vários autores: vermelha [10], preta [26], azul [12], todas com $P_{\text {del }}=1 \mathrm{~W}$.

Comparaçöes com Medidas em Phantoms

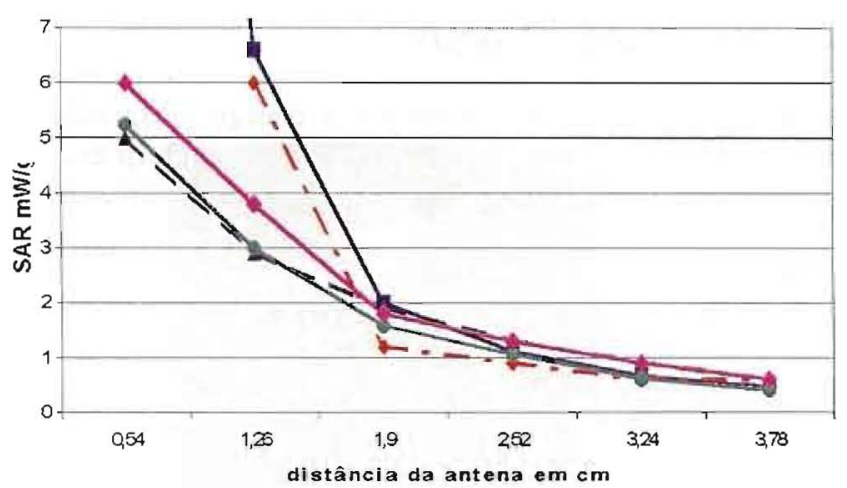

Figura 17. Valores obtidos nas atuais simulações: olho com antena frontal (azul) e hotspot interior ao crânio com antena lateral (verde), comparados com resultados medidos para antena lateral em modelo homogêneo (preta), phantom (vermelha) com $\mathrm{P}_{\mathrm{del}}=0.45 \mathrm{~W}$ [27] e (rosa) $\mathrm{P}_{\mathrm{del}}=0.6 \mathrm{~W}$ [28].

O importante aumento da SAR, com a diminuição da distância entre a antena e a cabeça, é observado em todos os casos. Isto é particularmente notado no olho, como vemos na Figura 18.

\subsection{CAPACIDADE COMPUTACIONAL}

Os algoritmos FDTD geralmente requerem massivos recursos computacionais. Se considerarmos que o domínio de cálculo, incluindo as bordas tem mais que 24 milhões de pontos $(268 \times 285 \times 316)$, nos quais são calculadas as diferentes componentes dos diferentes campos, elétrico e 
Comparações com Simulações sobre o Olho

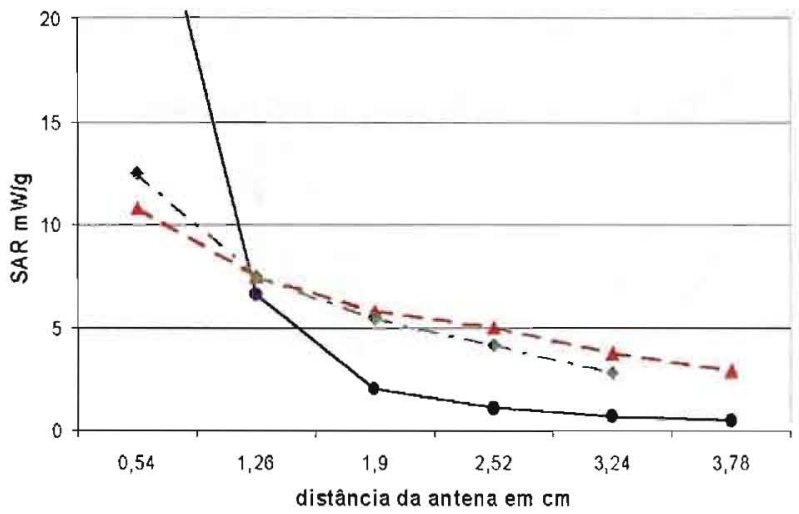

Figura 18. Gráfico da SAR no olho, com a antena frontal (azul) comparado com uma simulação semelhante para adulto (vermelha) [13] e criança (verde) [13]. Estas últimas com $P_{\text {del }}=1 \mathrm{~W}$.

magnético, não seria viável processar estas simulações com essa grandeza em computadores PCs usuais. Assim, como é necessária uma grande capacidade de memória (superior a $700 \mathrm{Mb}$ ) e de processamento, para realizar estas simulações, foi utilizado um computador de processamento paralelo CRAY T94 [29], com 5,2 GFLOP CPU, 2 GB RAM e unidade de disco de $9.5 \mathrm{~GB}$ SCSI, possibilitando assim estes trabalhos.

\section{ANTENAS PLANARES}

Alternativas visando minimizar a energia absorvida na cabeça têm sido investigadas. Antenas planares (p.ex., em "Microstrip", CPW - "Coplanar Waveguide", "Slot-line", etc.) têm sido descritas na literatura científica [30-41], podendo representar substanciais melhorias no desempenho dos telefones móveis, tanto em termos de diagrama de irradiação (p.ex., tipo "cardióide"), relação frente costas (p.ex., da ordem de $15 \mathrm{~dB}$ ), impedância de entrada, largura de banda, etc., resultando em melhoria da qualidade de comunicação, redução de consumo da bateria e dos riscos aos usuários.

Alguns autores desenvolveram antenas impressas para aplicações em telefones móveis, demonstrando algumas melhorias de desempenho (p.ex., em termos de eficiência de irradiação, etc.) em relação a antena monopolo convencional [30-40]. Estas antenas podem ser compactas, e com características de produção rentáveis provindas de matérias primas baratas e de fácil fabricação, além de serem robustas, pois sua estrutura não possui partes móveis ou salientes o que as torna ideal para transceptores portáteis. Além disto, devido a sua reduzida espessura, elas podem ser acomodadas em superfícies curvas ou planas como na capa de cobertura móvel do aparelho. Suas características de irradiação podem ser adaptadas para a aplicação desejada, como p.ex., seu diagrama de irradiação, relação frente costas, largura de banda, impedância de entrada, etc. Por exemplo, a PIFA ("Planar Inverted F Antenna") a BIFA ("Bent Inverted F Antennas") mostraram estas melhorias
[10, 35-36]. Também a antena espiral descrita em [40] mostrou resultados interessantes.

A seguir se descreverá sumariamente o projeto, realização e os resultados preliminares medidos para o protótipo experimental de uma antena tipo monopolo de um quarto de onda em microstrip desenvolvido.

\subsection{PROJETO}

A antena desenvolvida em microstrip é constituída de duas seções representadas na Figura 19. A primeira delas é uma linha de quarto de onda em aberto em sua extremidade e, portanto, apresenta semelhanças com uma antena monopolo, e a segunda opera como um transformador de quarto de onda, necessário para o casamento de impedância com o transmissor

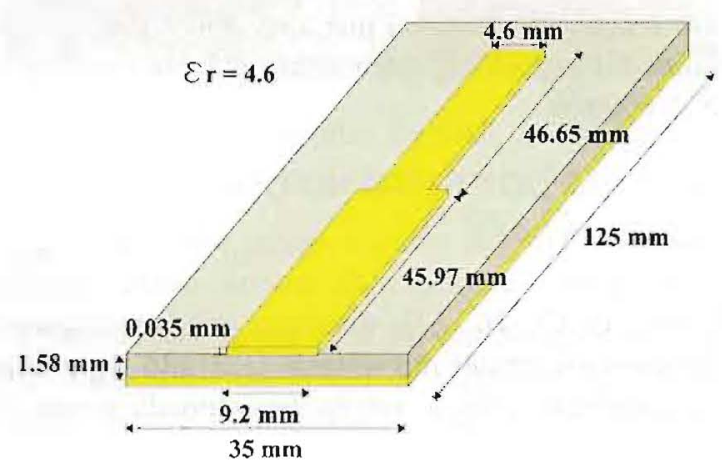

Figura 19. Representação da antena em microstrip utilizada.

Foram utilizadas equações bem estabelecidas [30-34, 4144] para o dimensionamento destas duas seções. $O$ transformador de quarto de onda é dimensionado para adaptar a baixa impedância na entrada do monopolo de quarto de onda à impedância vista dos terminais do transceptor portátil. Esta antena foi também modelada utilizando-se o método FDTD [41], que permite estimativa precisa dos campos na região próxima e distante, constituindo-se em importante ferramenta para o projeto e otimização destas antenas.

A frequêencia central escolhida foi $840 \mathrm{MHz}$. O substrato "Perstorp" tipo FR-4 V0 com constante dielétrica relativa 4,6 , espessura $1,58 \mathrm{~mm}$ e $0,035 \mathrm{~mm}$ de metalização foi utilizado. Na Figura 19 estão representadas as principais dimensões desta antena. A impedância de entrada do monopolo de quarto de onda foi estimada em 22,5 ohms, a impedância característica calculada do transformador de quarto de onda é 35,7 ohms, apresentando então em sua entrada uma impedância de 50 ohms. Foi utilizado um conector SMA para substituir o conector original, então mantendo menores possíveis as dimensões.

\subsection{MODELAMENTO FDTD}

Nesta simulação se analisa o comportamento da antena microstrip descrita acima, para a região próxima, através de um modelo simplificado e um algoritmo FDTD. A antena foi implementada dentro de um domínio contendo ar, para que o sinal se propagasse no espaço livre, ou seja, nestas simulações não foi incluída a cabeça como nas simulações anteriormente apresentadas. 
Para tanto, foram inicialmente determinadas dimensões apropriadas para a malha (matriz), escolhidas de forma que o modelo fosse o mais fiel possível. Assim teremos um domínio cúbico com células com dimensões espaciais: $\Delta \mathrm{x}=\Delta \mathrm{y}=\Delta \mathrm{z}=0,7 \mathrm{~mm}$ e as dimensões da antena são compostas de múltiplos inteiros desses elementos. Nesta malha, determina-se através de índices, o material para cada posição (célula). Com isso, a antena é "desenhada" nos diversos "cortes" da matriz (Figura 20).

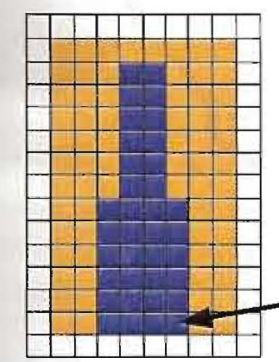

(a)

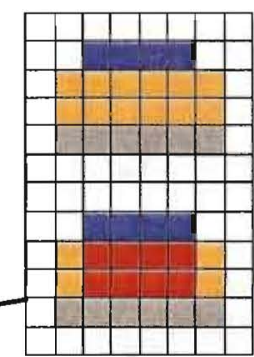

(b)

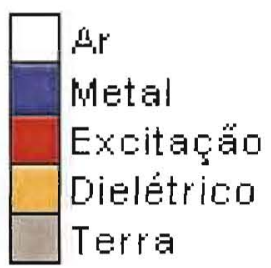

Figura 20. Representação de uma matriz contendo a antena microstrip, onde: (a) vista superior (b) vista em corte transversal.

Na Figura 20b está representado um corte transversal à antena, onde, na imagem inferior, está representada a excitação que é aplicada apenas nas células correspondentes à região restrita do dielétrico do plano inicial do metal indicada. Considera-se o metal como condutor perfeito, ou seja, com condutividade infinita, e, nas células em que há metal, as equações de diferenças finitas que o método propaga, são corrigidas de forma a eliminar as parcelas de campo dentro do metal, podendo de esta forma evitar a mudança de malha para representar espessuras de metal muito menores que as que poderiam ser descritas dadas as dimensões das células. Os principais parâmetros do dielétrico utilizado estão apresentados na Tabela 2.

\begin{tabular}{lll}
\hline \multicolumn{1}{c}{ Material } & $\varepsilon_{\mathrm{r}}$ & $\boldsymbol{\sigma}[\mathrm{S} / \mathrm{m}]$ \\
\hline Ar & 1 & 0 \\
Metal /Plano Terra & - & $\infty$ \\
Dielétrico (FR-4) & 4,6 & $2,1742 \times 10^{-3}$ \\
\hline
\end{tabular}

Tabela 2. Parâmetros dos materiais usados na simulação.

\subsection{SIMULAÇÃO}

Com a determinação do domínio do problema, todos os campos eletromagnéticos inicialmente são nulos. São inseridos, então, nos pontos referentes a excitação, campos que se propagarão por todo o domínio (antena/ar) ao longo das iterações. Após a convergência numérica do método, são disponibilizadas matrizes dos campos eletromagnéticos que serão transformadas em imagens para apreciação. A propagação dos campos pode-se perceber através de cortes transversais (Figuras 21 e 22), longitudinais (Figura 23) ou vista de topo (Figura 24).

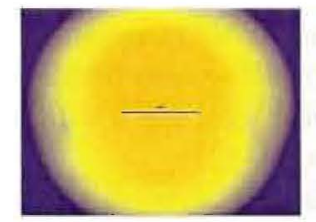

(a)

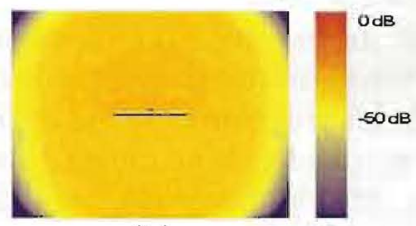

(b)
Figura 21. Imagens da propagação de campos eletromagnéticos através da antena microstrip, onde: (a) ocorre após 0,34 ns de propagação e (b) ocorre após 0,375 ns de propagação.

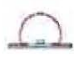

(a)

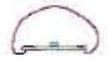

(b)

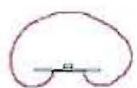

(c)
Figura 22. Imagens de cortes transversais da antena microstrip, onde: (a) ocorre após $0,69 \mathrm{~ns}$, (b) ocorre após $0,75 \mathrm{~ns}$ e (c) ocorre após 0,84 ns.

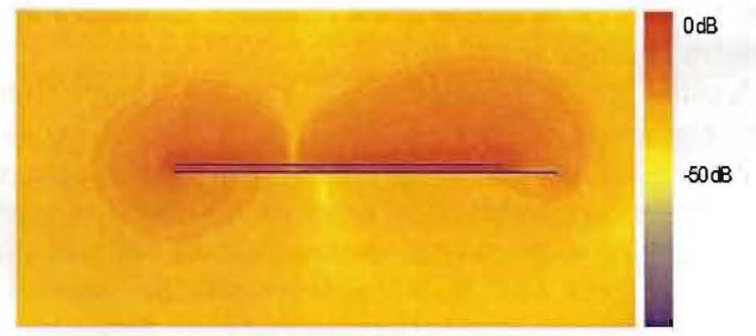

Figura 23. Campo elétrico propagado a partir da antena microstrip, para uma vista longitudinal após $0,86 \mathrm{~ns}$.

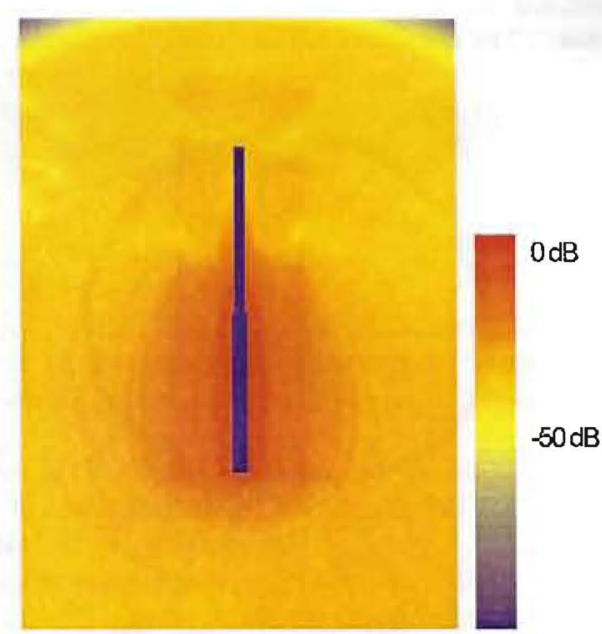

Figura 24. Propagação de campos eletromagnéticos a partir da antena microstrip, para uma vista de topo após $0,46 \mathrm{~ns}$.

\subsection{MEDIDAS}

A avaliação das características da antena tanto em campo próximo como em campo distante é tarefa difícil de ser realizada já que as condições ideais para a medida normalmente não existem e controlar o ambiente de modo a simular o espaço livre pode não ser possível.

Por conveniência utilizou-se uma antena monopolo no modo recepção acoplada a um analisador de espectro 
portátil Anritsu MS 2711 (princípio da reciprocidade) e a fonte transmissora (transceptor de trunking com frequências e potências programáveis) fixa em local distante o suficiente para ser considerada no campo distante [42].

Um critério adequado para definir esta distância é considerar que a antena sob teste seja iluminada por uma frente de onda praticamente plana e com diferenças de fase entre seu centro e sua borda maior não superior a $\lambda / 16$ [43]. Tipicamente a distância " $R$ " a partir do qual o campo pode ser considerado distante é dada pela equação:

$$
R \geq \frac{2 d^{2}}{\lambda}
$$

onde " $d$ " é a maior dimensão da antena. Para a freqüência de medida (cerca de $850 \mathrm{MHz}$ ) e para a antena em teste esta distância é de $0,7 \mathrm{~m}$.

Para aproximar o teste da condição de espaço livre foi utilizada a disposição de medição inclinada ("slant range") [41] de modo que a antena teste é colocada a uma altura maior que a antena transmissora.

Tal disposição tende a suprimir a onda refletida de terra e evita que outras reflexões degradem os valores de relação frente-costas existentes já que a onda que se dirige à antena também se dirige ao infinito.

Ajustes foram realizados em bancada (especialmente com elementos reativos e alargando a fita da seção do transformador de quarto de onda, que passou para uma impedância característica de cerca de 30 ohms), visando a otimização dos principais parâmetros da antena. Entre outros, a taxa de onda estacionária da antena foi substancialmente reduzida, ao longo da faixa desejada.

Os principais resultados preliminares obtidos serão mostrados a seguir. O diagrama de irradiação no plano horizontal está representado na Figura 25

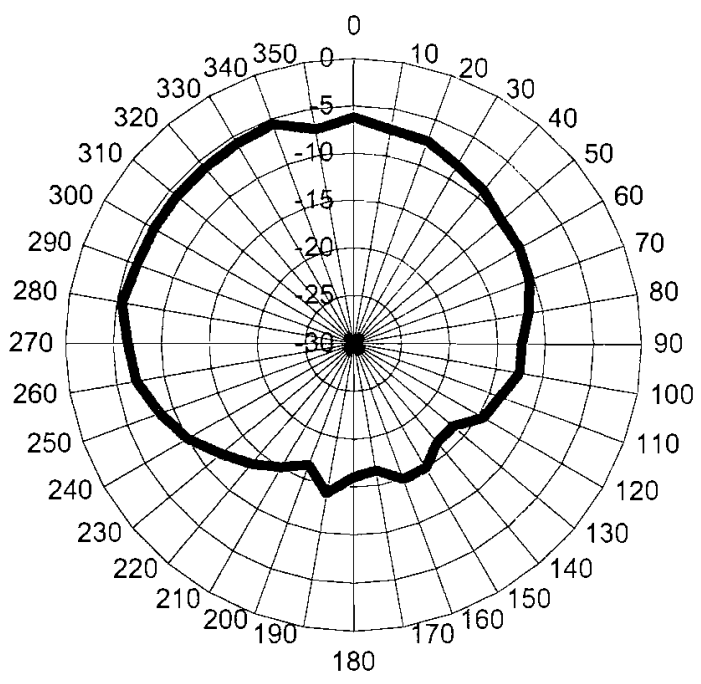

Figura 25. Diagrama de irradiação da antena microstrip no plano horizontal. A parte frontal da antena corresponde ao angulo $0^{\circ}$ e os valores de potência, em $\mathrm{dB}$, são em relação à potência equivalente irradiada por um monopolo de $\lambda / 2$.

Observa-se neste diagrama uma relação frente-costas da ordem de $13 \mathrm{dBs}$.

Na Figura 26 está mostrado o diagrama de irradiação no plano vertical medido para a parte frontal da antena (o plano da antena corresponde a $0^{\circ}$ ).

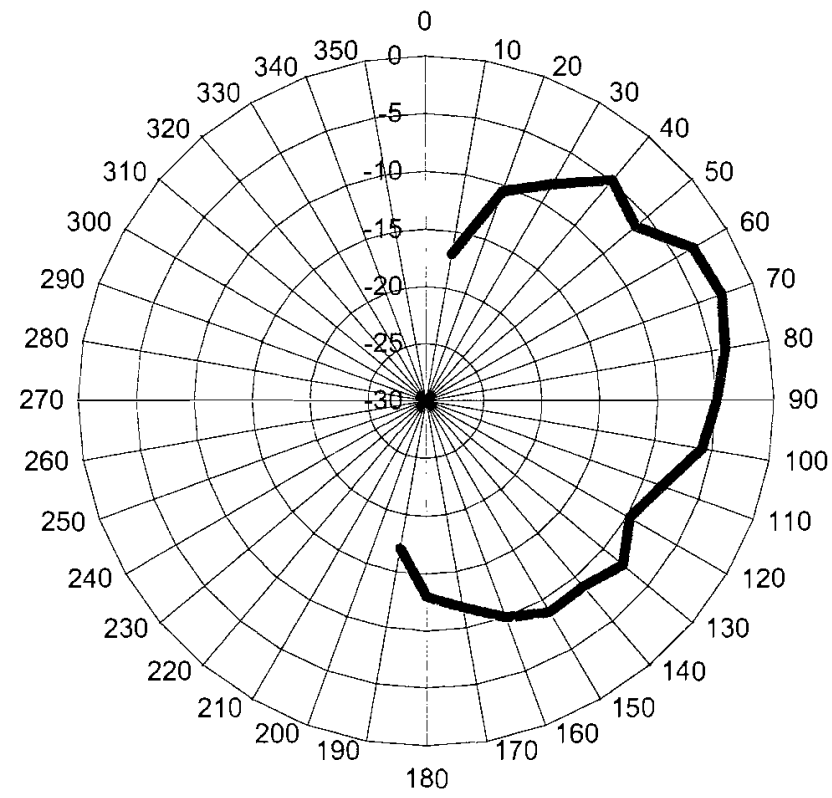

Figura 26. Diagrama de irradiação da antena microstrip no plano vertical. Onde $0 \mathrm{~dB}$ corresponde ao ganho de um monopolo de $\lambda / 2$ na direção de máximo ganho.

Na Figura 27 está mostrada a taxa de onda estacionária medida na entrada desta antena.

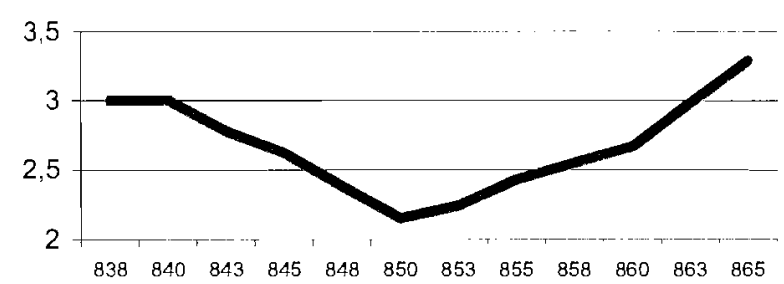

Figura 27. Taxa de onda estacionária medida na faixa de 837,5 a $865 \mathrm{MHz}$.

Observa-se desta figura que a taxa de onda estacionária medida para a antena microstrip na faixa de 840 a $860 \mathrm{MHz}$ mantém-se menor que três, o que é um resultado adequado para aplicações práticas.

De uma maneira geral, observa-se dos resultados preliminares medidos, que o diagrama de irradiação apresenta ângulos de abertura entre os pontos de meia potência da ordem de $180^{\circ}$ no plano horizontal e de cerca de $90^{\circ}$ no plano vertical, relação frente-costas da ordem de $13 \mathrm{~dB}$, taxa de onda estacionária na entrada menor que 3, para a faixa de freqüências entre 840 e $860 \mathrm{MHz}$.

Estes resultados preliminares certamente poderão ser melhorados. Também, com a utilização de substratos com constantes dielétricas mais elevadas, obtém-se uma redução substancial nas dimensões destas antenas permitindo uma melhor integração nos aparelhos portáteis.

\section{COMENTÁRIOS E CONCLUSÕES}

Foram discutidos os principais efeitos biológicos dos campos eletromagnéticos não-ionizantes e foi feita uma apresentação dos principais aspectos do algoritmo 
desenvolvido para simular a taxa de absorção específica (SAR) na cabeça e nos olhos do usuário do telefone celular. Foram apresentados os resultados simulados e comparados com os simulados e medidos por outros autores. Entre outros resultados, observa-se que quando a antena está muito próxima da cabeça (p.ex., menos que $2 \mathrm{~cm}$ ), os limites das normas disponíveis são superados. No olho, para distâncias menores que cerca de $4 \mathrm{~cm}$ aquelas normas já são superadas. Como estas normas são baseadas essencialmente nos efeitos térmicos, existe a possibilidade (se os efeitos não-térmicos forem definitivamente comprovados) que elas sejam modificadas para niveis mais restritivos.

Os novos serviços com maior capacidade de informação via telefones móveis (p.ex., WAP - "Wireless Application Protocol", dados, imagens, etc.) e com consequentemente maior potência emitida, deverão também necessitar antenas mais eficientes sob o ponto de vista de energia utilizada para a comunicação em relação à absorvida na cabeça. Desta forma, novas antenas irradiando mais no sentido oposto a cabeça do usuário, como o tipo de antena em microstrip preliminarmente descrita neste trabalho, devem ser desenvolvidas. Estas antenas dcverão representar solução adequada a ser utilizada brevemente em uma nova geração de telefones móveis. O método de FDTD certamente poderá contribuir substancialmente para o projeto e a otimização destas antenas.

\section{Agradecimentos}

Os autores agradecem aos profs. Marco T.M.B. Vilhena ? Jorge Lisbôa, aos Engs. R. S. Machado e S. L. Severo peia colaboração no desenvolvimento do algoritmo de simulaçào, bem como ao Eng. P. Serafini nas medidas com a antena em microstrip.

\section{REFERÊNCIAS}

[1] ICNIRP Guidelines: "Guidelines for Limiting Exposure to Time-Varying Electric, Magnetic and Electromagnetic Fields (Up to $300 \mathrm{GHz}$ )", International Commission on NonIonizing Radiation Protection, "Health Physics", April 1998, vol. $74, \mathrm{n}^{\circ} .4$, pp. 494-522.

[2] American National Standards Institute (ANSI). "IEEE C95.11991: IEEE Standard for Safety Levels with Respect to Human Exposure to Radio Frequency Electromagnetic Fields, $3 \mathrm{kHz}$ to $300 \mathrm{GHz}$ ", The Institute of Electrical and Electronics Engineers, Inc., 345 East 47 Street, New York, NY 10017-2394, USA.

[3] Salles, A. A. A de, "Biological Effects of Microwaves and RF" ("Invited Paper"), 1999 SBMO/IEEE MTT-S International Microwave and Optoelectronics Conference, 1999, Rio de Janeiro, pg. 611-617

[4] Salles, A. A. A. de, "Efeitos Biológicos dos Telefones Celulares Portáteis", Revista da Sociedade Brasileira de Telecomunicações, vol. 11, n". 1. dezembro 1996, pg. 71-80.

[5] Moseley, H., Medical Physics Handbooks 18. "Non-Ionizing Radiation", Chap. 3 - Biological Effects of Microwaves and RF, pp. 38-61.

[6] Bernhart, J. H., "Non-Ionizing Radiation Safety: Radiofrequency Radiation, Electric and Magnetic Fields", Physics on Medicine and Biology, vol. 37, n'. 4, 1992. pp. 807-844

[7] Bronzino, J. D., (ed.), "The Biomedical Engineering Handbook", CRC Press \& IEEE Press., 1995, pp.1388-1389. and Section IX - "Biologic Effects of Non-ionizins Electromagnetic Fields", pp. 1380-1440.

[8] Grant, L. J., "Practical Aspects of Non-Ionizing Radiatior Protection', The Hospital 'Physicists' Association. Leeds 1981.

[9] "International EMF Project", http://www.who.int/emf/.

[10] Jensen, M. A., and Rahmat-Samii, Y., "EM interaction of handset antennas and a human in personal communications". Proc. of the IEEE, vol. 83, n. 1. January 1995, pp. 7-17.

[11] Okoniewski, M.. and Stuchly. M. A., "A study of the handset antenna and human body interaction", IEEE T-MTT. vol. 44. no. 10. October 1996. pp. 1855-1864.

[12] Watanabe. S.. et al.. "Characteristics of the SAR distributions in a head exposed to electromagnetic fields radiated by a hand-held portable radio", IEEE T-MTT, vol. 44, $\mathrm{n}^{\circ}$. 10, Oct. 1996. pp. 1874-1883.

[13] Dimbylow, P. J., and Gandhi, O. P., "Finite-Difference Time-Domain Calculations of SAR in a Realistic Heterogeneous Model of the Head for Plane-Wave Exposure from $600 \mathrm{MHz}$ to $3 \mathrm{GHz}$," Phys. Med. Biol., vol. 36, pp.1075-1089, Aug. 1991.

[14] Salles, A. A., Fernández, C. R. e Bonadiman, M., "Simulação da Taxa de Absorção na Cabeça do Usuário do Telefone Celular", anais do IX Simpósio Brasileiro de Microondas e Optoeletrônica, agosto 2000, João Pessoa, PB.

[15] Salles, A. A., Fernández, C. R. e Bonadiman, M.. "Distância da Antena e Potência Absorvida na Cabeça do Usuário de Telefone Celular", anais do XVIII Simpósio Brasileiro de Telecomunicaçôes, setembro 2000, Gramado, RS.

[16] Fischetti, M., "The Cellular Phone Scare", IEEE Spectrum. June 1993, pp. 43-47.

[17] Stuchly, M. A., "Mobile Communication Systems and Biological Effects on their Users". The Radio Se:ta Bulletin, no. 275, December 1995, pp.7-13.

[18] de Pomerai. D., et al., "Non-Thcrmal Heat-Shock Response to Microwaves", Nature. vol. 405, 25 May 2000, pp. 417+18 .

[19] de Pomerai. D., et al. "Microwave Radiation Induces a HeatShock Response and Enhances Growth in the Nematode Caenorhahditis Elegans", IEEE Trans. On MTT, vol. 48, $\mathrm{n}^{\circ}$. 11. November 2000. pp. 2076-2081.

[20] Taflove, A.. "Computational Electrodynamics- the Finite Difference Time Domain Method", Artech House 1995, ISBN 0-89006-792-9.

[21] Taflove. A., "Advances in Computational Electrodynamicsthe Finite Difference Time Domain Method", Artech House 1998, ISBN 0-89006-834-8.

[22] Bérenger, J. P.. "Perfectly Matched Layer" for the FDTD Solution of Wave-Structure Interaction Problems", IEEE Trans. on Antennas \& Propagation, vol. 44, 17". 1 January 1996.

[23] Bérenger, J. P.. "Improved PML for the FDTD Solution of Wave-Structure Interaction Problems", IEEE T. Antennas \& Prop. vol. 45, ñ. 3 March 1997.

[24] http://www.vhd.org.br

[25] CENELEC, "Basic Standard for the Measurement of Specific Absorption Rate Related to Human Exposure to Electromagnetic Fields from Mobile Phones $(300 \mathrm{MHz}-3$ GHz)", Rev. Final Draft, TC-211, April 2000.

[26] Chen, $H$. and Wang. $H$, "Current and SAR Induced in a Human Head Model by the Electromagnetic Fields Irradiated from a Cellular Phone", IEEE Trans. on Microwave T\&T, vol. $42, n^{\circ} .12$ December 1994

[27] Hombach, V. et al, "The Dependence of EM Energy Absorption Upon Human Head Modeling at 900 Mhz", IEEE Trans. on Microwave T\& T, vol. 44. $n^{\circ}$. 10, October 1996.

[28] Schiavoni, A., Bertotto, P., Richiardi, G. and Bielli, P. "SAR Generated by Commercial Cellular Phones - Phone 
Modeling, and Measurements", IEEE T-MTT, vol. 48, $\mathrm{n}^{\circ} .11$, November 2000.

[29] http:/www.cesup.ufrgs.br

[30] James, J. R., Hall, P. S. and Wood, C., "Microstrip Antenna: Theory and Design", Peter Peregrinus, 1981, ISBN: 0 906048575.

[31] Pozar, D. M. and Schaubert, D. H., "Microstrip Antennas The Analysis and Design of Microstrip Antennas and Arrays", IEEE Press, 1985, ISBN 0-7803-1078-0.

[32] Barthia, P., Rao. K. V. S. and Tomar, R. S., "MillimeterWave Microstrip and Printed Circuit Antennas", Artech House, 1990.

[33] Van Der Pauw. L. J., "The Radiation of Electromagnetic Power by Microstrip Configurations". IEEE Trans. On MTT, vol. MTT-25, n'. 9, September 1977, pp. 719-725.

[34] Belohoubek, E. and Denlinger, E., "Loss Considerations for Microstrip Resonators", IEEE Trans. On MTT, vol. MTT-23, June 1975, pp.522-526.

[35] Jensen, M.A., and Rahmat-Samii, Y.. "The Electromagnetic Interaction Between Biological Tissue and Antennas on a Transceiver Handset", 1994 IEEE MTT-S International Microwave Symposium, pp. 367-370.

[36] Rahmat-Samii, Y., "Novel Antennas for Personal Communications Including Biological Effects", SBMO/IEEE MTT-S IMOC'95 Proceedings, pp.295-308.

[37] Sanad, M., and Amant. N. H., "An Internal Integrated Microstrip Antenna for PCS/Cellular Telephones and Other Hand-held Portable Communication Equipment", Microwave Journal, July 1998, pp.64-77.

[38] Deal, W. R., Qian, Y., and Itoh, T., "Planar Integrated Antenna Technology", Microwave Journal, July 1999, pp. 128-144.

[39] Sanad, M., and Hassan, N., "Compact Internal Multiband Microstrip Antennas for Portable GPS, PCS, Cellular and Satellite Phones", Microwave Journal, August 1999, pp. 9098
[40] Bezerra, J. M., Junqueira, C. e Richards, F.P. "Antenas de Faixa-Larga de Polarização Circular Impressas em Microfitas", XVIII Simpósio Brasileiro de Telecomunicações, Gramado, RS, setembro 2000.

[41] Maloney, J. G., Smith, G. S., and Scott, W. R., "Accurate Computation of the Radiation from Simple Antennas Using the Finite-Difference Time-Domain Method", IEEE Trans. On AP, vol. 38, nº. 7, 1990, pp. 1059-1068.

[42] Balanis, C., "Antenna Theory Analysis and Design", John Wiley \& Sons 1997, ISBN 0-471-59268-4.

[43] Jasik, H. "Antenna Engeneering Handbook", Mc.Graw-Hill 1961.

[44] Sainati, R.. "CAD of Microstrip Antennas for Wireless Applications", Artech 1996, ISBN 0-890-06-562-4.

Álvaro A. de Salles é graduado em Engenharia Elétrica na Universidade Federal do Rio Grande do Sul (UFRGS) em 1968, M. Sc. na Pontifícia Universidade Católica do Rio de Janeiro (PUC-RJ) em 1971, Ph.D. na Universidade de Londres em 1982, e atualmente é professor adjunto no Departamento de Engenharia Elétrica da UFRGS.

Claudio R. Fernández é graduado em Engenharia Elétrica na Universidade Estadual de Campinas (UNICAMP) em 1996 e atualmente é professor no Departamento de Engenharia Elétrica na Universidade Federal do Rio Grande do Sul (UFRGS).

Mateus Bonadiman é acadêmico em Engenharia Elétrica na Universidade Federal do Rio Grande do Sul (UFRGS). 